\title{
Students' Responsiveness to the Implication of Culture-oriented Courses in EFL Classrooms
}

\author{
Samia Amari ${ }^{1} \&$ Zouaoui Merbouh ${ }^{2}$ \\ ${ }^{1}$ Department of English, Faculty of Letters, Languages, and Arts, Djillali Liabes University, Sidi Bel \\ Abbès, Algeria \\ ${ }^{2}$ Department of English, Faculty of Letters, Languages, and Arts, Djillali Liabes University, Sidi Bel \\ Abbès, Algeria \\ Corresponding author: Samia Amari, Djillali Liabes University, Sidi Bel Abbès, Algeria. \\ Email: samia_amari@hotmail.com
}

Received: April 8, 2019

Accepted: May 24, 2019

Online Published: June 1, 2019

doi: 10.23918/ijsses.v5i4p126

\begin{abstract}
English has increasingly become an inevitable part of educational curriculum at schools and universities. Accordingly, a number of considerable efforts are devoted to popularize EFL teaching among learners. For instance, a significant body of research has been provided by scholars as an attempt to investigate the factors underlying the accumulation of that language under various circumstances. Thus, the study at hands aims to draw attention to the ways cultural contents are incorporated into classes where English is taught to non-native speakers. Furthermore, it offers a rationale for the teaching of culture in EFL contexts and the possible solutions that aim to increase students' intercultural awareness. As an attempt to reach the research objectives, it is of unavoidable importance to shed light on students' degree of responsiveness to cultural contents. This is done through examining the ways in which the chosen participants experience and perceive culture and its implementation into courses.
\end{abstract}

Keywords: Sensitivity, Awareness, Responsiveness, Intercultural Competence

\section{Introduction}

With the growing trend of globalization, it becomes common to include teaching and learning practices based on cultural backgrounds with the aim of promoting an understanding of the nature and meaning of culture through an input grounded on distinct cultural elements from which students can negotiate meaning. In fact, it is inevitable to seek for ways to improve education by attempting to solve any problem that may be encountered by learners. Teachers are active decision-makers in the way they create practically-oriented contexts that spread knowledge among learners in a number of ways. Thus, the need to tackle that topic is progressively becoming a subject of interest among pedagogues.

Being a learner of a foreign language is not an easy task; it creates challenging experiences that may be similar to some of the same frustrating situations that may happen to those who enter into a new land and find themselves obliged to respond and adapt to new conditions and deal with foreigners. It is obviously seen that successful communication results from an understanding of cross-cultural characteristics and differences across both cultures. Thus, a number of skills should be raised among students to help them become good mediators between the native and target cultures. With the growing trend of globalization, it becomes common to include teaching and learning practices based on cultural backgrounds with the 
aim of promoting an understanding of the nature and meaning of culture through the comprehensive analysis of an input grounded on distinct cultural elements. Effective interaction across cultures needs negotiation of meaning through developing both culture- specific and culture-general features. Highlighting cultural themes helps attain intercultural objectives and sensitivity. In order for learners to develop sympathy and appreciation towards the related culture, a number of procedures have to be implemented for the aim of creating attitudes of tolerance and awareness. Consequently, FL instruction should go beyond grammar and vocabulary by creating socio-cultural contexts based on authenticity and attempts to cross-cultural tolerance.

Culture, as it is viewed by many scholars, is that multifaceted whole combining features that define a population's set of interests, practices, views, beliefs, morals and guiding principles. The lack of familiarity with the cultures related to the target language may negatively impede the process of accumulating the knowledge needed to become successful speakers. In recent decades, researchers are attempting to best satisfy students' needs regarding the language system as a whole believing that teaching a foreign language is inaccurate and incomplete without the integration of the related culture.

\section{Theoretical Framework}

When referring to a specific language, one automatically seeks to know about the native speakers of that language and tries to discover their social traits, customs, beliefs, practices, way of thinking, etc; accordingly, most people relate language to culture in a number of ways. Thus, the relationship between language and culture is a controversial topic. This is due to the fact that language is a part of culture and culture reflects language.

\subsection{What is Culture?}

A number of attempts have been made to theorize definitions that cover any dimension related to culture. Trivonovich (as cited in Croft, 1980) announces that there exist more than 450 definitions for the term "culture" as it is one of the most complicated words in the English language in terms of denotations. This view is reinforced by Stern (1992) who insists that culture is a term whose meaning is notoriously difficult to be defined. This drives specialists to offer countless definitions that are sometimes different in terms of taxonomy and the intended meaning. In this respect, Byram (1989) explains that there is a multiplicity in defining that concept among scholars. Along with the same idea, Apte (1994, p. 2001), asserts that "Despite a century of efforts to define culture adequately, there was in the early 1990s no agreement among anthropologists regarding its nature". In general all that shape people's identity may be referred to as culture, which envelops all aspects of man's life including behaviours, beliefs, values, and the overall norms that are inherited and shared by a population. Culture is a multifaceted and complex notion whose aspects need to be clearly classified and defined in a number of ways and from multiple perspectives. Thus, the present article has as objectives to clearly review scholars' attempts to define it and to relate it to teaching/learning contexts. Culture is the overall integrated patterns of characteristics that shape a population's thoughts, communicative routines, actions, customs, ideas, beliefs, values and the different norms of a given society. It formulates the way in which that society views things and shows enthusiasm as well as rejection towards some acts. 
The word culture can be defined in a number of ways. It generally refers to a series of patterns that describe how the members of a certain society perceive their social norms and rituals and how to put them into practice.The representation of these actions and ideas makes these members different comparing to others and shapes their social identity. In this respect, Kroeber \& Kluckhohn (1952, p. 181) describe it as:

Patterns, explicit and implicit, of and for behaviour acquired and transmitted by symbols, constituting the distinctive achievements of human groups, including their embodiment in artifacts; the essential core of culture consists of traditional (i.e. historically derived and selected) ideas and especially their attached values; culture systems may, on the one hand, be considered as products of action, on the other, as conditional elements of future action.

Similarly, Moran (2001) defines the notion of culture as "the great achievement of people as reflected in their history, social institutions, works of art, architecture, music and literature" (p. 24). Culture is, then, the set of attitudes, values, beliefs, and behaviours transmitted from one generation to the other for the purpose of preserving a population's heritage.

\subsection{Dimensions of Culture}

The sub-division of culture has been referred to as "big-C culture" or "high culture", and "little-c culture" or "low culture". Meadows (2016) explains that the distinction between both concepts has come to be emphasized in the 1960s with the shift of interest towards the social and cultural aspects of the target language. These pedagogical attempts have as objectives to give students insights into the cultures that characterize the native speakers of the target language by exploring their ways of thinking, behaving and all that make students eager to perceive otherness in a normal way; accordingly, they develop an interest in the daily lives and practices of the English-speaking communities within cultural contexts.

\subsubsection{Big-C Culture}

According to Bourdieu (1990), high culture refers to experiences while low or little culture refers to morals. The twofold process combines all characteristics that make up the whole traits of a society's culture. It may refer to that part of culture which is often noticeable by everybody. As examples, one may mention special holidays, different forms and works of art, literary productions, food, architecture, etc.

As far learning foreign languages is concerned, the incorporation of Big-C culture into courses entails any knowledge that reflects the social products of a given community in terms of geographical features, historical information, literary works, etc. This approach stresses the exposure to what we refer to as the study of civilization for foreign language learners. For instance, this aspect may be extended in classes by reflecting courses of geography, historical events, national symbols, educational, political, economic and religious facts. However, focusing on this dimension as the only way to discover about the target culture may lead to poor knowledge from the part of students in terms of beliefs, habits and traditions of the foreign population. This in turn directs to low levels of cultural awareness and responsiveness to situations that demand a certain level of readiness to know about otherness. 
As a dimension, it might be effective in making students knowledgeable of the different components of culture, and helping them build communicative skills and sociolinguistic paradigms. The importance of big-C culture as an integral part of foreign language education started to gain popularity among EFL experts and thinkers in the last decades. This creates a need to shift towards exploiting other sociocultural aspects or what is referred to as "little-c culture".

\subsubsection{Little-c Culture}

In addition to focusing on the daily practices of members of cultural groups, it is also recommended to highlight the other abstract notions that define populations. In this respect, Kramsch (2006) states that the other part of culture is often related with the conventional aspects of a given society; this aspect may also be an enjoyable experience for many learners. For instance, it can help them discuss the way people perceive things and how they get socialized in cultural contexts.

One of the most significant concepts of culture is 'small culture' which states people's ways of thinking and sharing social values. It also covers the principles and reasons under which actions are made, shared and changed. In fact, little-c culture is the invisible part of the cultural iceberg model. It may define the hidden part reflecting a specific area surrounded by a group of people whose origins, language and values are the same; this may include lifestyles, non-verbal ways of communication, ideologies, attitudes, norms, morals, religious beliefs, myths, stereotypes and clichés. Many researchers assume that this facet of language teaching can be explored by learners in implicit ways. Applying this approach in language teaching may lead to consider culture as a social phenomenon, which depicts pictures of the shared activities and behaviours of the foreign community. This may be done through examining themes such as beliefs, attitudes, values, food, style of living, accustomed traditions, etc. Nevertheless, it is insufficient to focus only on one of the two dimensions apart from the other meaning that language learning can be enlarged to include both small-c and big- $\mathrm{C}$ cultures.

\subsection{Culture and Language Teaching}

The co-existence of culture as an integral part of language teaching has always been a matter of interest among scholars and educators. For instance, there should be some theories determining its usefulness as one of the most significant language components.

Language and culture have a co-dependent relationship as language is the medium through which most of our knowledge about culture is obtained. They are inseparable in the sense that culture not only dictates who talks to whom, about what, and how the communication proceeds, it also helps to determine how people encode messages, the meanings they form for messages, and the circumstances under which various messages may be sent, noticed, or interpreted. Consequently, culture plays a vital role in teaching for it helps learners understand what they are learning and make them capable of reacting to multicultural contexts; therefore, without the study of culture, foreign language instruction is inaccurate and incomplete. In the same line of thought, Brown (1994) has stressed the importance of teaching culture when teaching the foreign language; he affirms that they are intertwined so that one cannot separate the two without losing the significance of the other. 


\subsection{The Development of Aims in EFL Instruction (From Linguistic Competence to Intercultural Competence)}

It is obviously seen that foreign language teaching has witnessed many changes in the methods used to spread knowledge and in the objectives of classroom instruction. At the early stages, the overall objective of language teaching was to acquire a general knowledge about the language being taught. In fact, learning languages was marked by ignoring the importance of socio-cultural rules in the learning process i.e. the focus was on the ability to use what is learned in a correct way. However, the skills that enable to appropriately communicate and respond to different social situations were deserted. Yet, in the second half of the 20th century, there had been a shift in emphasis from linguistic to communicative purposes. For instance, scholars realized that it was not sufficient to produce grammatically correct expressions without being able to fittingly use those expressions depending on the social context. For instance, the attempts of Moore (1996) refer to teaching cultural contents through focusing on the 4-F approach (Folk-dances, Festivals, Fairs, Food); then, the focus changed gradually from historical and geographical data to knowledge on values, beliefs and thoughts of other group members. Subsequently, in the 1990s, the intercultural dimension emerged as the main objective of FL instructional curricula. As a result, the term "intercultural competence" was introduced by Michael Byram, professor at Durham university in the United Kingdom. In 1997, Byram defines that capability as bringing two cultures into contact; he clarifies that teaching any foreign language should be based on developing the skills of noticing how cultures are different and how they are related in terms of similarities. Byram (1988, p. 9) defines the intercultural individual as someone who has knowledge of one or, preferably, more cultures and social identities and has a capacity to discover and relate to new people from the contexts for which they have not been prepared yet. Chambers (2001) mentions the three qualities of the intercultural speaker as someone who show a multicultural competence, a sensitivity to other social identities, and an ability to mediate and relate the native with the other cultures.

As outlined above, the past decades have witnessed the development of aims in foreign language education, and resulted in a focus on culture teaching. Pretceille (2001) declares that learning is not simply concerned with the accumulation of other languages, it is rather an understanding of people's way of thinking and behaving through their language and their culture(s). She distinguishes two shifts in teaching objectives: one is the shift from historical and geographical to cultural contents, while the other is a shift from cultural to intercultural competence as a key component to enhance sensitivity and awareness among learners. Foreign language learners are required to produce an infinite number of phrases to express their wants and ideas using appropriate and simple language structures. Accordingly, they should be in contact with the cultures associated with the language they are learning by being exposed to a wide range of data on cultural themes.

\section{Objectives of the Proposed Study}

In the past, language education was basically concerned with the development of learners' abilities in grammar and vocabulary. Yet, an increasing attention started to be given to the language system as a whole without ignoring socio-cultural features. Accordingly, many studies have been carried out as an attempt to provide standards for successful foreign language instruction based on the enlargement of intercultural communication. 
The present study addresses the relevance of courses of cultural contents in EFL instruction. It attempts to inspect the effect of such dimension on the learning process. To reach the desired goals, it is of primary importance to scan the perceptions of students towards the implementation of culture-oriented topics in educational settings. Assessing learners' responsiveness to the culture that reflects the target language they are learning helps in determining whether the incorporation of culture into teaching is advantageous. Furthermore, the study attempts to find out the possible strategies and didactical techniques that may facilitate the amalgamation of culturally mediated instruction into the curriculum.

\section{Research Questions and Hypotheses}

Since effective teaching is teachers' major concern, Algeria, like other countries, is certainly interested in improving learning situations; however, some learners are still facing great difficulties. In the light of what has been said earlier, the study addresses three major research questions:

1. What are the attitudes of EFL students towards the English language, and the culture of the people whose native language is English?

2. Are students interculturally competent?

3. Can culturally mediated contents reduce students' negative stereotypes on foreign cultures?

Based on the aforementioned research questions, three hypotheses have been proposed as a tentative way of formulating possible answers:

1. Most students have ethnocentric judgments and stereotypes about the cultures of the TL.

2. Most students are not interculturally competent.

3. Culturally mediated instruction reduces students' negative stereotypes on foreign cultures.

\section{Sampling}

To explore the highlighted phenomenon; it is essential to examine students' inability to cope with their stereotypes and determine the main reasons that stand behind such problem. The population under examination is a well-defined group of individuals consisting of 40 among whom four were sometimes absent. The class was chosen from Djillali Liabes University of Sidi Bel Abbes; mainly, third year students. Students' age level ranges from 18 to 20; they are provided with the required information regarding the questionnaire and they are informed that the participation in the study is voluntary and their personal information would remain confidential throughout the whole work.

\section{Data Collection Instruments}

While gathering data for the study, both quantitative and qualitative data are of equal importance. Yet, the present article has as a primary concern to quantify the gathered data for the purpose of extending the degree to which the problematic is affecting students' perceptions and academic achievements. For instance, quantitative methods provide the researcher with numerical data that can be measurable in numbers and symbolized in percentages, and have enabled her to get a valuable insight into the highlighted situation. For instance, to examine the attitudes of learners, the researcher uses a questionnaire which includes both types of questions (close and open-ended) organized into five rubrics, all of which contain a number of related questions. Thus, dividing the questionnaire into parts facilitates the gathering and the interpretation of the findings. The questionnaires have been given to all learners 
(40); hence, each part of the questionnaire aims to identify and explore a specific issue and the purposes are clearly outlined in the table below:

Table1: Purposes of the Questionnaire

\begin{tabular}{|l|l|}
\hline Parts & Purposes \\
\hline 1 & $\begin{array}{l}\text { To get general information about respondents } \\
\text { To acquire knowledge about their attitudinal tendencies. }\end{array}$ \\
\hline 3 & $\begin{array}{l}\text { To measure learners' cultural knowledge about people from other countries } \\
\text { namely whose native language is English }\end{array}$ \\
\hline 4 & $\begin{array}{l}\text { To examine learners' exposure to the cultures of the English-speaking } \\
\text { communities (the exposure inside and outside the classroom) }\end{array}$ \\
\hline 5 & $\begin{array}{l}\text { To determine learners' attitudes concerning the cultures and the people who } \\
\text { speak English as their mother tongue. } \\
\text { differences and whether they are culturally aware of differentiation among } \\
\text { cultures. }\end{array}$ \\
\hline
\end{tabular}

As mentioned in the table above, the main concern of the questionnaire designed for students is to gather general information about their perceptions on the relevance of implementing cultural contents while teaching the foreign language. To reach the designed objectives, different questions have been prepared and classified in rubrics to facilitate the interpretation.

\section{Analysis and Interpretations of the Main Findings}

As far as the first rubric is concerned, one of the questions sheds lights on students' attempts to extensively read works in their free time. For instance, this question may be helpful in determining the extent to which they get exposed to foreign cultures. The results indicated that some participants use extensive reading. Yet, the purpose is to know whether they read in English or not. Accordingly, the researcher adds another question that determines the languages they use while reading. The responses to that question show that 12 students preferred to read in Arabic, 18 read in French, 7 read in English, 2 read in German and 1 preferred Spanish books. This shows that they are not exposed to English to a high extent. The last question of the first rubric aims to determine the students' free-time activities: 12 said that they practise sport, 11 of them listen to music, 10 works, and 7 read literary works. This shows that only few respondents attempt to enlarge their background knowledge in English while others are interested in other activities. The results of this question are presented in the chart below: 


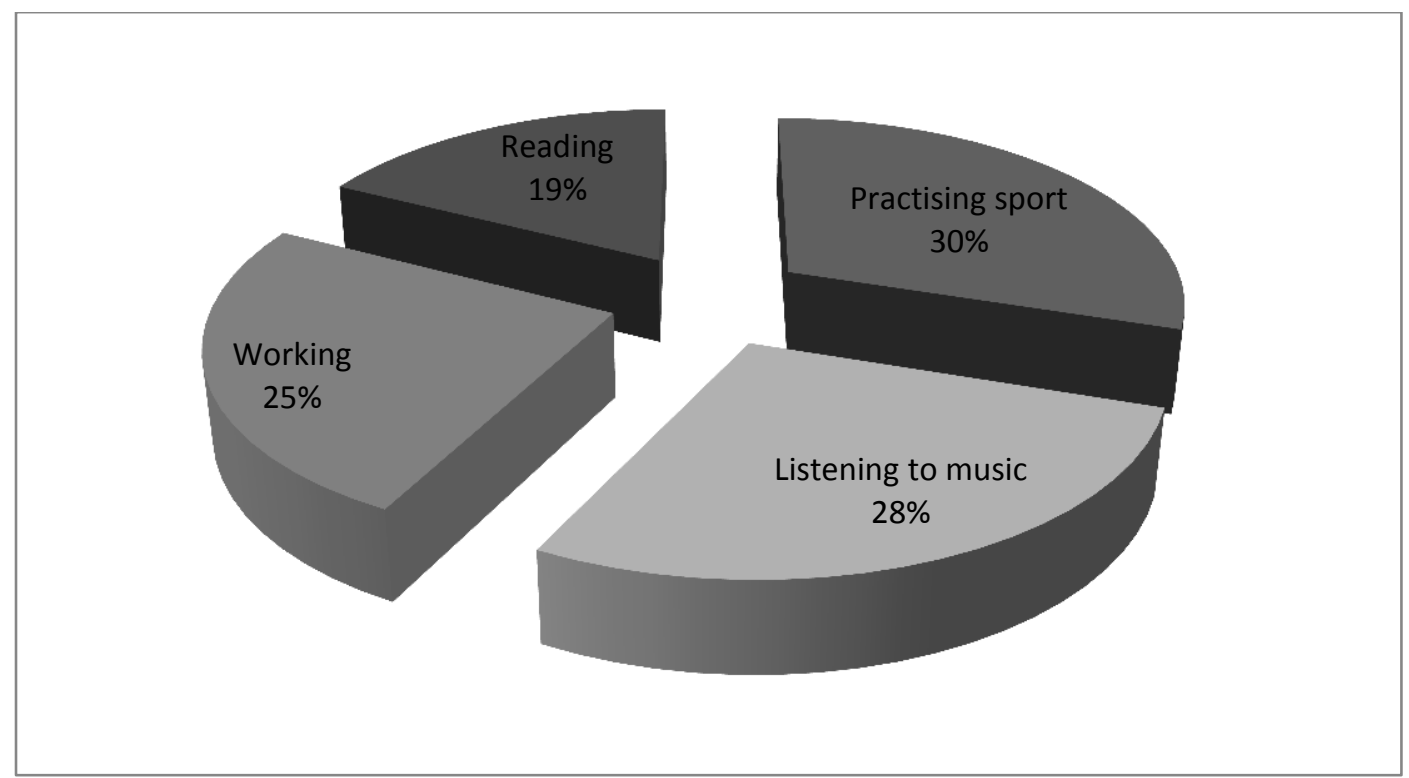

Figure1: Learners’ Free-time Activities

As an introductory question to the second part of the questionnaire, the researcher has asked participants to define culture by explaining what is meant by that word in general. The results indicate that a great number of participants reflected knowledge about the aspects related to culture (one defines it as "traditions", another one relates it to "past events", and others associate it with "religion"). What can be seen is the fact that there was no complete definition in terms of all aspects related to culture, which means that they still need to widen their knowledge on what constitutes the population's cultural heritage. Moreover, asking participants whether they know something about the people whose mother tongue is English provides the researcher with valuable information in the sense that the majority of respondents confirmed that they are somehow familiar with these cultures; yet, their definitions and comments could not cover the required aspects. An additional question has been of a great importance in providing detailed descriptions of learners' familiarity with the related cultures. This is realized through asking them to tick one of aspects provided in the list below:

Table 2: Learners' Familiarity with Cultural Aspects

\begin{tabular}{|l|l|l|}
\hline Cultural aspects & Britain & USA \\
\hline History & $30 \%$ & $25 \%$ \\
\hline Geography & $27.50 \%$ & $25 \%$ \\
\hline Politics & $22.50 \%$ & $30 \%$ \\
\hline Literature & $12.50 \%$ & $7.50 \%$ \\
\hline Ethnicity & $5 \%$ & $7.50 \%$ \\
\hline Daily-life practices & $0 \%$ & $2.50 \%$ \\
\hline Values and beliefs & $2.50 \%$ & $2.50 \%$ \\
\hline
\end{tabular}


The findings revealed that participants are not familiar with all aspects including history, geography, politics, literature, ethnicity, daily-life routines, values and beliefs. They rather show familiarity with historical as well as geographical aspects. For instance, what can be noticed is that less attention from the part of participants is given to values and ethnicity with no interest in daily-life practices. This may be interpreted in a lack of cultural awareness regarding beliefs, ethnic classifications, practices and traditions. Bearing in mind that the aim of this rubric is to provide necessary information about the amount of exposure to cultural components related to the target language, the researcher attempts to establish an interconnection between the instructional environment and the external one, so that she can examine the role of the teacher as well as the external factors that reflect familiarity with the target language and culture.

The results revealed that students are not extremely exposed to the cultures related to the English language. This lack of exposure is caused by the constraints of completing the programme designed for third year students. Therefore, other interventions are needed outside the classroom to widen students' cultural knowledge regarding the English-speaking communities.

The researcher has introduced another question on participants' attempts to compare their native and other cultures. Subsequently, a high percentage represented the native one i.e. $60.50 \%$. Another proportion perceived the French people as superior, 3 students chose the British, and 2 preferred the American culture. As a result, one can assume that whenever we provide a situation of comparison among countries, they show preferences towards their country due to the existence of differences. Those who consider their native culture as the superior one were asked to present some of the reasons behind their choices. For instance, some of them related their responses with one's valuable cultural heritage and social identity as well. The numerical results are illustrated in the chart below:

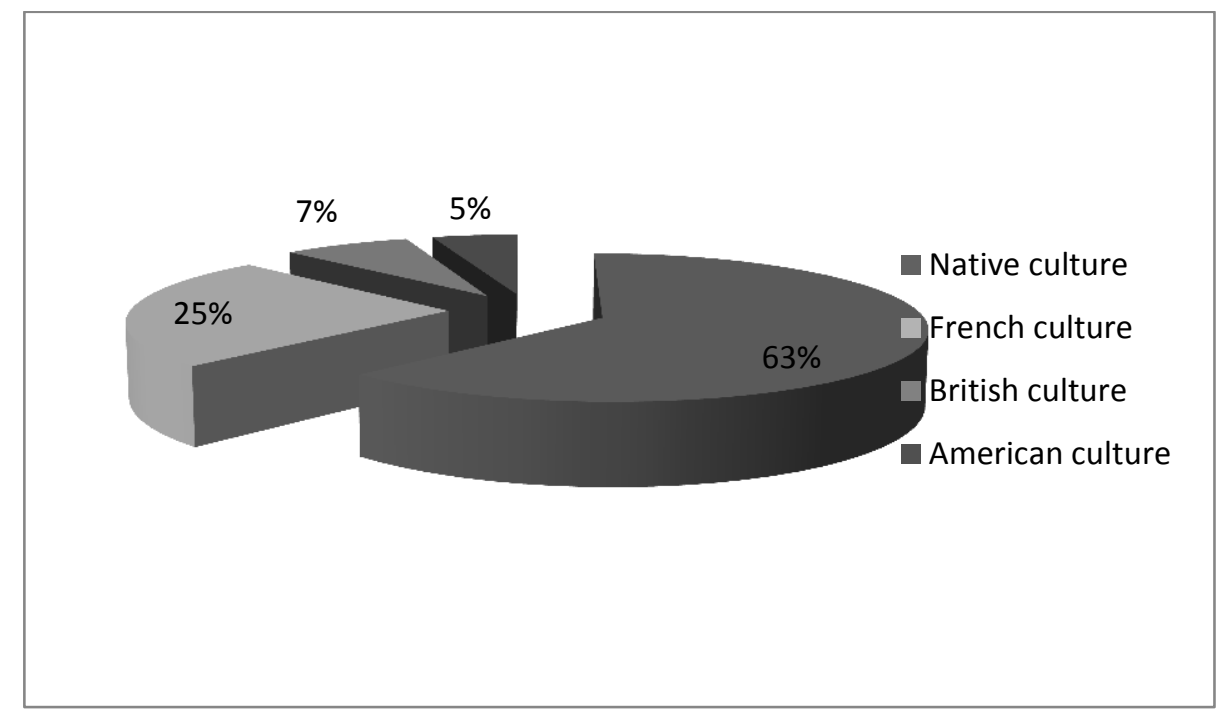

Figure 2: Students' Perceptions on the Native and Foreign Cultures

Moreover, the researcher has proposed a number of questions that may in one way or another contribute to a better understanding of the situation related to learners' degree of cultural awareness and 
perceptions towards culturally mediated instruction. The questions as well as answers are then outlined in the table below:

Table 3: Students' Degree of Cultural Awareness

\begin{tabular}{|l|c|c|c|c|c|}
\hline \multicolumn{1}{|c|}{ Questions } & $\begin{array}{c}\text { Not at all } \\
\text { important }\end{array}$ & $\begin{array}{c}\text { Not very } \\
\text { important }\end{array}$ & $\begin{array}{c}\text { Somehow } \\
\text { Important }\end{array}$ & Important & $\begin{array}{c}\text { Very } \\
\text { Important }\end{array}$ \\
\hline $\begin{array}{l}\text { Do you think that learning } \\
\text { culture is as important as } \\
\text { learning the target language? }\end{array}$ & 16 & 09 & 10 & 3 & 2 \\
\cline { 2 - 6 } & $40 \%$ & $22.50 \%$ & $25 \%$ & $7.50 \%$ & $5 \%$ \\
\hline $\begin{array}{l}\text { Is culture learning important for } \\
\text { your peers? }\end{array}$ & 17 & 15 & 4 & 2 & 2 \\
\cline { 2 - 6 } & $42.50 \%$ & $37.50 \%$ & $10 \%$ & $5 \%$ & $5 \%$ \\
\hline $\begin{array}{l}\text { Is culture teaching important for } \\
\text { your instructors? }\end{array}$ & 08 & 11 & 18 & 2 & 1 \\
\cline { 2 - 6 } & $20 \%$ & $27.50 \%$ & $45 \%$ & $5 \%$ & $2.50 \%$ \\
\hline $\begin{array}{l}\text { Is it necessary to visit a foreign } \\
\text { land to be a successful speaker? }\end{array}$ & 18 & 14 & 3 & 2 & 3 \\
\cline { 2 - 6 } & $45 \%$ & $35 \%$ & $7.50 \%$ & $5 \%$ & $7.50 \%$ \\
\hline
\end{tabular}

As far as students' perceptions on the relevance of culture, one of the questions attempts to examine learners' responsiveness to the implementation of cultural knowledge. Consequently, some respondents agreed that knowledge is needed on both cultures while others preferred to deal with either the native or the foreign one in separate ways. This may give an idea about the lack of awareness regarding the knowledge needed for the acquisition of intercultural competence in terms of learning about differences among cultures.

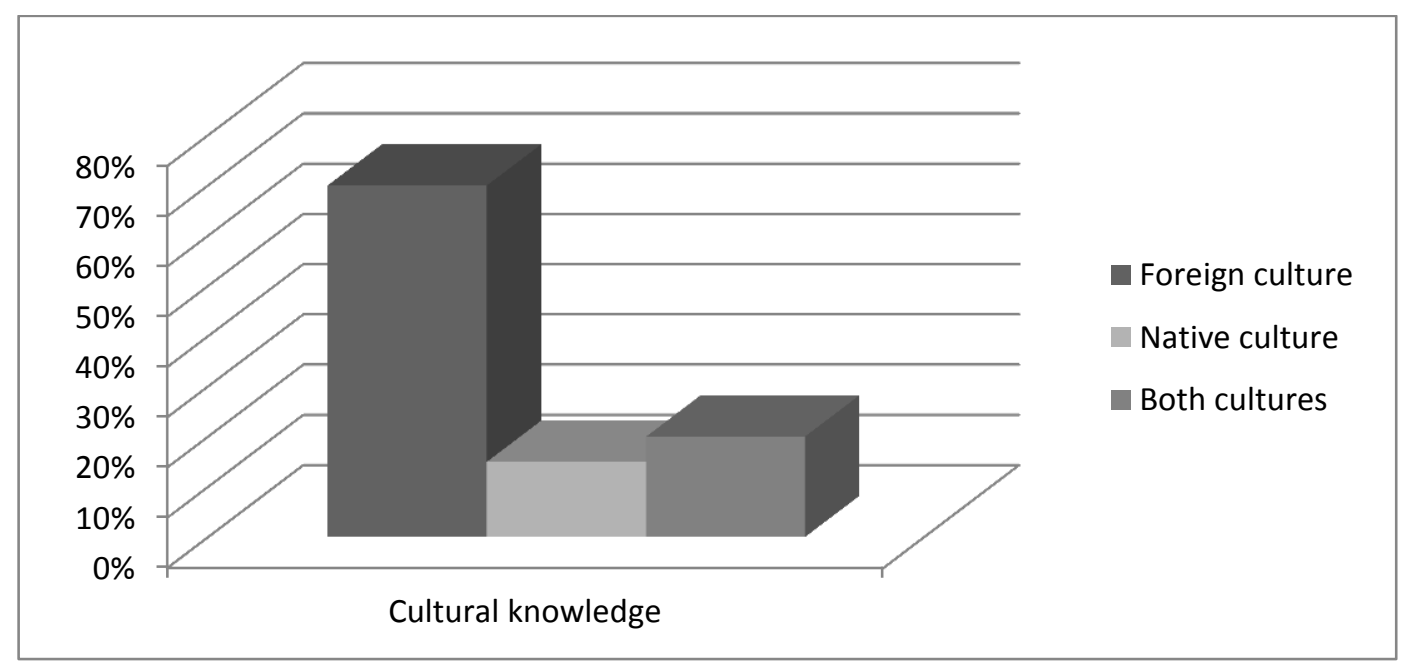

Figure 3: Students' Viewpoints on the Required Cultural Knowledge 
Being knowledgeable of differences and similarities among cultures is one of the most significant stages of intercultural learning. For instance, the last question of the questionnaire administrated to participants aims to shed light on the suggested problematic by asking participants about their learning objectives. The results obtained through that multiple-choice question revealed that most participants showed an interest in the productive skills while only few of them planned to develop the receptive ones. This may lead one to affirm that the concern of most learners is still restricted to the development of speaking abilities and written productions. Subsequently, other skills are neglected including what we refer to as the fifth skill.

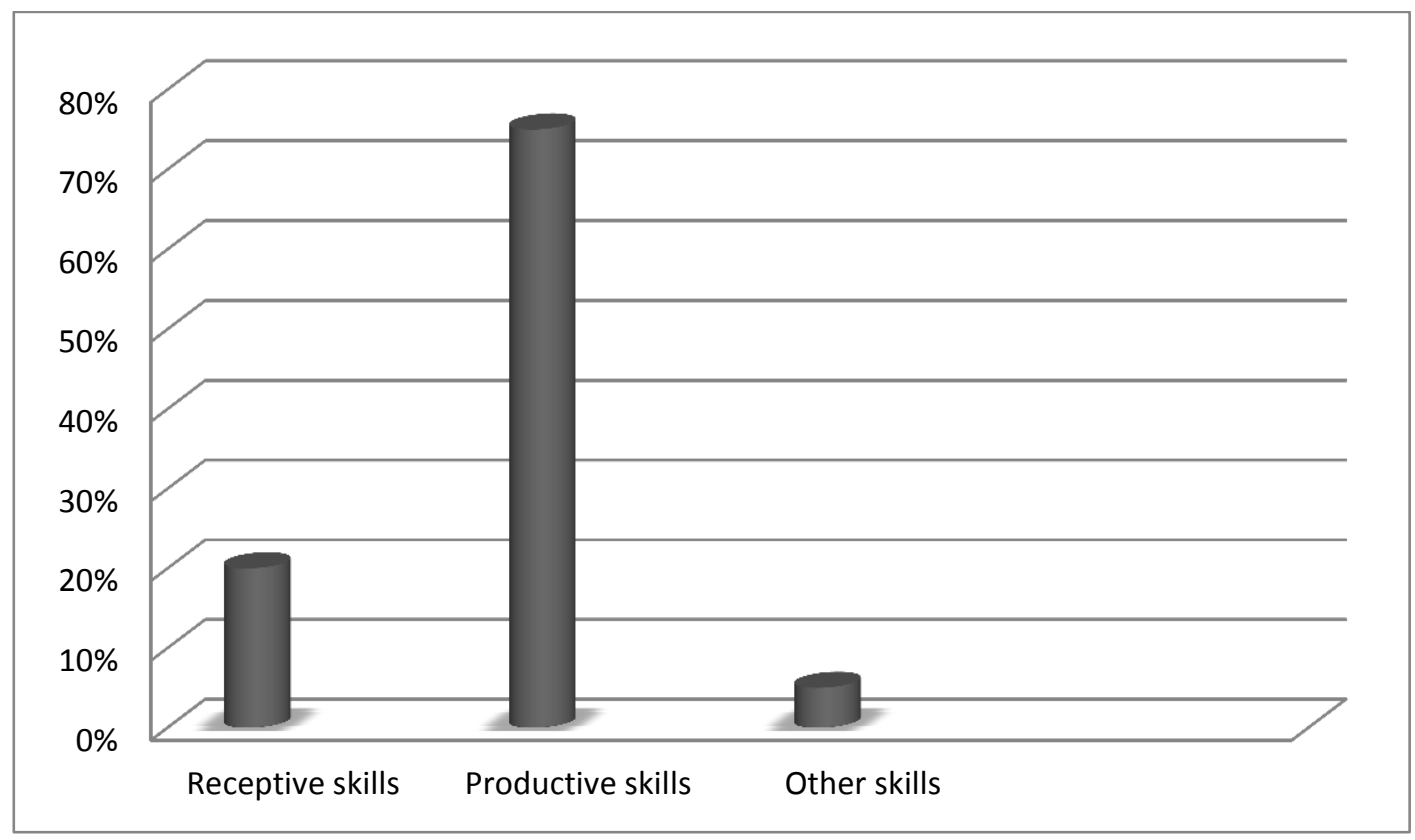

Figure 4: Learning Objectives

\section{Discussion of the Obtained Results}

Most of the information gathered was an attempt to find answers to the research questions formulated in the first phase of the study. Using quantitative approaches of data collection has provided the researcher with insightful ideas in relation to the topic under investigation by offering statistical information that can be discussed for the purpose of describing the situation in a detailed way. As an attempt to give detailed descriptions of the phenomenon, the obtained answers have been interpreted in numbers and analytical descriptions that reflect students' attitudes towards the cultures associated with L1 and TL. In the line of what has been mentioned in the early stages of the study, the questionnaire encompasses a number of questions organized in rubrics to facilitate the access to information in a well-organized way.

In general, the responses of the questionnaire indicate that the selected group of learners shows insufficient awareness regarding the perceptions towards similarities and differences among cultures. In fact, making attempts to acquire cultural knowledge is one of the most important steps towards culturally mediated instruction and responsiveness to data of cultural contents. In the line of what was mentioned 
previously, the present paper proceeds to a systematized analysis of the data collected through quantitative means of collection. The results show that it is of permanent importance for teachers to implement the techniques and interventions that may in one way or another increase students' appreciations of other cultures, mainly the English-speaking countries. Based on evidence from the data collection tools, the researcher realizes that much of their familiarity with cultural knowledge is in terms of their free-time activities including music, movies, network and TV series. Yet, they neglect other sources including literary works, academic tasks, workshops and research projects. It is worth noting that they frequently use extensive reading in other languages such as French and Arabic. The answers revealed that most students are not familiar with all that concern otherness; some of them are familiar with historical aspects, others are interested in arts whereas only few respondents show an excitement towards values, ethnicity, literature, and the different daily-life activities. This reflects a lack of awareness regarding the significance of enlarging one's cultural knowledge in terms of social identities and differentiation.

Moreover, the questions revealed the extent to which culture-oriented contents are implemented in courses and outside classrooms as well. It is commonly believed that the classroom practices may explicitly or implicitly enhance learners' cultural knowledge and help measure their degree of awareness of the necessity of culture learning along with language learning. Having interpreted the questions related to the exposure to culture outside the classroom makes one confirm that the exposure is insufficient to explore cultural data as a result of students' lack of interest to acquire cultural knowledge. Hence, it is always recommended to implicitly include the fifth skill in courses even when being concerned with the enlargement of other skills and teaching aims. Furthermore, the findings reveal that most of the classroom content in different subject matters is concerned with the English-speaking countries, namely Britain and USA. The instructors show a certain readiness to know about these cultures as they are supposed to be mediators who can bridge the gap between the native and foreign cultural features for their students. What can be noticed is the fact that the university curriculum for civilization courses for third year students focuses mainly and solely on the American culture, whereas the British one is introduced to second year students. However, the teaching time allocated to civilization for first year students is distributed among both culture (the British in the first semester and the American in the second one).

It can be seen that students' unfamiliarity with the related culture is mostly related to the lack of exposure to culturally mediated contents that foster one's understanding of differences across cultures. It can be seen then that any lack of motivation to discover the characteristics of other peoples particularly those of the English-speaking countries leads to lower levels of responsiveness to courses of cultural contents and negative perceptions. This may be the result of the lack of intercultural experiences that enlarge learners' cultural repertoire with the linguistic one. It can be concluded then that students' unfamiliarity with the related culture is mostly related to the lack of exposure to culturally mediated contents that foster one's understanding of differences across cultures. It can be seen that any lack of motivation to discover the characteristics of other peoples particularly those of the English-speaking countries leads to lower levels of responsiveness to cultural contents and negative perceptions. This may be the result of the lack of intercultural experiences that enlarge learners' cultural repertoire along with the linguistic one. 
Based on the above-mentioned explanations and on the evidence generated from the procedures followed to accomplish this study, one can find answers to the four formulated questions suggested in the early stages of the research process. Thus, it has been concluded that the hypotheses proposed by the researcher can be confirmed.

1. Most students have ethnocentric stereotypes about foreign cultures.

2. Most students are not interculturally competent.

3. Culturally mediated instruction can reduce students' negative stereotypes on otherness.

Having a good command of the target language is not sufficient to meet the needs of learners in terms of the ability to maintain successful communication. It is also necessary to know how to implement instructional techniques and methods that facilitate the implication of culture-oriented courses in EFL settings. Thus, teachers are recommended to keep in touch with current researches and are supposed to be as familiar as possible with their learners' process of learning, difficulties, needs and perceptions.

\section{Conclusion}

People's strong sense of identity and group membership lead to the development of stereotypical perceptions that refuse differentiation among social groups in terms of cultural characteristics. Research has shown that intercultural awareness cannot be acquired automatically. It is rather a process that needs to be learned and reinforced through a set of intercultural experiences. In other words, teachers are responsible of engaging learners in different classroom practices that are built upon the exposure to the aspects that reflect other cultural identities. Having knowledge about otherness is what makes language learners competent in terms of intercultural mediation and awareness. Thus, syllabus designers can play an important role in reducing the problem discussed in this study in the sense that they can make EFL courses evolve towards an intercultural direction.

\section{References}

Apte, M. (1994). Language in sociocultural context. In: Asher R.E. (Ed). The encyclopaedia of language and linguistics. Vol. 4 (pp. 2000-2010). Oxford: Pergamon Press

Brown, H. D. (1994). Principles of language learning and teaching. New Jersey: Prentice-Hall, inc.

Byram, M. (1988). Foreign language education and cultural studies. Language, Culture and Curriculum, $1,15-31$.

Byram, M. (1989). Cultural studies in foreign language education. England: Clevedon.

Byram, M. (1997). Teaching and assessing intercultural communicative competence. Clevedon, UK: Multilingual Matters.

Chambers, A. (2001). Intercultural communication: The role of virtual mobility. In M. Kelly, I. Elliott \& Fant, L. (Eds.). Third level, third space: Intercultural communication and language in European higher education, pp. 47-61.

Croft, K. (1980). Readings on English as a second language. Massachusetts: Winthrop Publishers, Inc.

Kroeber, A. L., \&Kluckhohn, C. (1952). Culture: A critical review of concepts and definitions. Cambridge, Massachusetts, U.S.A.

Moore, Z. T. (1996). Teaching and testing culture: Old questions, new dimensions. International Journal of Educational Research, 25, 595-606.

Moran, P, R. (2001). Teaching culture: Perspectives in practice. Boston: Heinle \& Heinle. 
Pretceille, A, M. (2001). Intercultural communication: Elements for a curricular approach. In M. Kelly, I. Elliott \& L. Fant (Eds.). Third Level, third space: Intercultural communication and language in European higher education, pp. 121- 141.

Stern, H. H. (1992). Issues and options in language teaching. Oxford: Oxford University Press.

Valdes, J, M. (1986). Culture bound: Bridging the cultural gap in language teaching. Cambridge: Cambridge University Press. 